\title{
PRESENTACIÓN SERIE DE ARTÍCULOS SOBRE EL PLAN DE GESTIÓN DEL CONJUNTO CONVENTUAL DE SAN FRANCISCO
}

Saadia Sánchez Vegas

Directora y Representante Oficina de UNESCO en Quito y Representación para Bolivia,

Colombia, Ecuador y Venezuela

Recibido: 23 - julio - 2015, aprobado 20 - noviembre - 2015

\section{Resumen}

La UNESCO en Quito presenta artículos dedicados a la restauración del convento San Francisco, planifica con miembros asociados a la conservación de sitios culturales y naturales que requieren protección para garantizar la transmisión del acervo patrimonial a las generaciones venideras, ideando acciones para conservar un valioso inmueble con obras de Caspicara, Legarda, Olmos; artistas de la Escuela Quiteña que dejaron importantes obras a la iglesia de San Francisco. Diferentes entidades realizan inversiones en la conservación cultural, por lo que la UNESCO con la Cooperación Italiana para el Desarrollo, realizó un plan de gestión, a largo plazo, explicado a través de cuatro artículos vinculados cada uno al plan de restauración, proporcionando información detallada sobre el diagnóstico en bienes muebles; por último, se hace una descripción y análisis de la metodología.

Palabras clave: UNESCO, acervo, patrimonio, conservación, restauración.

\begin{abstract}
UNESCO Quito presents articles dedicated to the restoration of the convent of Saint Francis, plannifies with members associated with the conservation of cultural and natural sites that require protection to ensure the patromonial heritage transmission to the future generations, devising actions to conserve a valuable property with Caspicara, Legarda and Olmos artworks; artists of the Quito School who left important artworks to the church of San Francisco. Different companies make investments in cultural conservation, so that UNESCO with the Italian Cooperation for Development, held a management plan, long-term, explained through four articles linked each one to the restoration plan, providing detailed information about diagnosis in movables, finally a description and analysis of the methodology is made.
\end{abstract}

Keywords: UNESCO, heritage, heritage conservation, restoration 
La Oficina de UNESCO en Quito y Representación para Bolivia, Colombia, Ecuador y Venezuela tiene el honor de presentar una serie de artículos dedicados al Plan de Gestión Integral del Conjunto Conventual de San Francisco de Quito, espacio medular del Centro Histórico de Quito, inscrito en la Lista del Patrimonio Mundial en el año 1978.

La UNESCO, única agencia de Naciones Unidas con un mandato específico en cultura, está conformada por 195 Estados Miembros y 10 miembros asociados. En sus 70 años de existencia ha promulgado instrumentos de aplicación internacional, con el propósito de generar marcos de referencia y de acción para cada una de sus distintas áreas de trabajo. La Convención sobre la protección del Patrimonio Mundial Cultural y Natural, aprobada por la Conferencia General en 1972, es uno de los instrumentos de mayor relevancia e impacto en el ámbito internacional. Dicha Convención tiene como objetivos apoyar y propiciar el diseño y la implementación de estrategias de conservación y prevención en sitios culturales y naturales, que requieren protección para garantizar el disfrute y la transmisión del acervo patrimonial a las generaciones venideras.

En el marco de la movilización y la cooperación sinérgica de instituciones del ámbito patrimonial, se han adelantado importantes acciones para la conservación de este admirable inmueble y el valioso patrimonio que alberga, contando entre sus bienes muebles con obras de grandes artistas como Manuel Chili "Caspicara”, Bernardo de Legarda y José Olmos; maestros de la Escuela de Arte Quiteña que dejaron en la Iglesia de San Francisco obras emblemáticas que edifican la identidad cultural de Quito y de Ecuador, como la Virgen Alada o San Francisco Seráfico.

Varias entidades de cooperación nacional e internacional, entre las que destacan el antiguo Fondo de Salvamento del Patrimonio Cultural (FONSAL), el Instituto Nacional de Patrimonio Cultural (INPC), el Municipio del Distrito Metropolitano de Quito y la Agencia Española de Cooperación Internacional para el Desarrollo (AECID), realizaron importantes inversiones de recursos financieros y dedicación de recursos humanos en la conservación y preservación del Conjunto Conventual de San Francisco de Quito. Sin embargo, sus 5.000 m2 de construcción y miles de obras de arte, representan un gran desafío para el mantenimiento sostenible de este conjunto conventual.

Es así que la UNESCO y un comité de expertos nacionales e internacionales y en estrecha coordinación con instituciones públicas y privadas, mediante el financiamiento de la Cooperación Italiana al Desarrollo, diseñaron un Plan de Gestión Integral para el Conjunto Conventual de San Francisco de Quito, con el propósito de consolidar un sistema de gestión del patrimonio del conjunto en seguimiento al criterio sustantivo de sostenibilidad. A estos fines, se contemplaron una serie de actividades necesarias para su conservación en el largo plazo, garantizando la transparencia en la administración de los recursos, a través de un fideicomiso que facilita la rendición de cuentas.

Esta serie de cuatro artículos presentados en la prestigiosa revista académica Anales, invitan a conocer a través de la experiencia de expertos en la materia pa- 
trimonial, la innovadora aproximación del Plan de Gestión Integral del Conjunto Conventual de San Francisco de Quito en la conservación de este invaluable espacio. El primer artículo, elaborado por Alcira Sandoval Ruiz, especialista responsable del Sector Cultura de la Oficina de UNESCO en Quito y Representación para Bolivia, Colombia, Ecuador y Venezuela, incluye la reseña y explicación del plan de gestión, abordando los antecedentes, objetivos, mecanismos de funcionamiento y acciones ejecutadas en el contexto del mismo.

Los tres artículos restantes que integran esta serie, se vinculan a cada uno de los componentes del plan. Así, el artículo de la autoría del Instituto Metropolitano de Patrimonio (IMP) del Municipio del Distrito Metropolitano de Quito alude a los componentes mueble e inmueble del plan, refiriendo los trabajos realizados por esta institución en los componentes ya referidos, muy específicamente dos de las actividades indicadas como necesarias en el plan de gestión: la restauración de los bienes muebles del ala norte de la basílica menor de San Francisco, así como los trabajos para el saneamiento de la humedad en el área colindante del Convento de San Carlos con las criptas de San Francisco. Ambos trabajos tuvieron como resultado importantes descubrimientos que nos dejan saber sobre el legado e historia de este conjunto conventual.

El artículo tocante al componente mueble, realizado por el consultor y experto ecuatoriano en bienes muebles, Israel Zambrano, proporciona información detallada sobre el diagnóstico de bienes muebles elaborado a los fines de la conceptualización del plan y, de la misma forma, ofrece un resumen de las actividades ejecutadas en estos primeros años de implementación, en consideración a las buenas prácticas.

Por último, el artículo referente al tema de turismo sostenible, escrito por el experto internacional Jordi Tresserras, hace una descripción y análisis de la metodología, resultados y potencial del conjunto conventual en el marco de las prácticas propias del turismo sostenible, no solo a nivel local sino internacional.

Esta serie de artículos proporciona una visión global de lo que ha sido el diseño y la instrumentación de este proyecto piloto, caracterizado por su carácter singular en la región y por los significativos desafíos planteados en su ejecución.

Consideramos que la construcción de sinergias entre diversos actores públicos y privados sobre la base de criterios de complementariedad y corresponsabilidad, constituye un valioso aporte del plan de gestión, lo que nos ha permitido conocer y concitar el gran interés de estos actores en la preservación y conservación del patrimonio mundial cultural quiteño.

Concluyo, agradeciendo muy especialmente a todas las instituciones que apoyaron este proyecto desde sus inicios en febrero de 2013: el antiguo Ministerio Coordinador del Patrimonio, el Ministerio Coordinador de Talento Humano, el Ministerio de Cultura y Patrimonio, el Instituto Nacional de Patrimonio Cultural (INPC), el Municipio del Distrito Metropolitano de Quito, a través de su Instituto Metropolitano de Patrimonio (IMP) y la Empresa Pública Quito-Turismo, ya que su sólido compromiso permitió movilizar las acciones y obtener los recursos para la consolidación de este novedoso plan. 
No menos importante es el agradecimiento a los consultores, quienes tuvieron la ardua tarea de dar forma al documento del plan, Jordi Tresserras, Carolina Castellanos, Dora Arízaga e Israel Zambrano.

Asimismo, expresamos nuestra profunda gratitud a la Comunidad Franciscana, quienes preocupados por la preservación del patrimonio del cual son custodios, nos abrieron las puertas para desarrollar un trabajo conjunto y buscar la mejor manera de lograr la conservación sostenible del Convento Máximo de San Francisco de Quito.

Finalmente, es imprescindible agradecer el apoyo y compromiso de FIDUCIA S.A. Administradora de Fondos y Fideicomiso, de la Universidad Tecnológica Equinoccial (UTE), del Ministerio de Turismo, la Arquidiócesis de Quito y de otras instituciones del ámbito cultural que se han sumado y continúan sumándose a esta significativa iniciativa para la conservación de este emblemático ícono del centro histórico de Quito, patrimonio mundial. 